\title{
IRMANDADE AFETADA PELA ATROFIA MUSCULAR PERONEAL DE CHARCOT-MARIE-TOOTH COM POSSIVEL VARIANTE DO FENOMENO DA ANTECIPAÇÃO
}

\author{
AGUINALDO GONGALVES * \\ JEOVA BARRCS DA SILVA **
}

A atrofia muscular peroneal apresenta uma atrofia neurogênica basicamente caracterizada por perda de força muscular distal, lentamente progressiva, afetando as pernas antes dos braços. Inicia-se geralmente na infância, mas há ampla variação entre familias diferentes quanto à idade de estabelecimento; há apenas discreto efeito na longevidade e fertilidade (Pratt, 1967) ${ }^{15}$.

$O$ início, curso, distribuição do comprometimento muscular, herança e pés cavum da doença de Dejerine-Sottas assemelham-se com a nosografia da atrofia peronal, sendo admitido, por alguns autores, que se trata de variantes da mesma afecção, embora já se tenha firmado que espessamento dos nervos, miose, nistagmo e alterações sensoriais caracterizam a individualização primária (Dyck, 1963) ${ }^{7}$.

Sua frequência é difícil de ser avaliada, desde que muitos casos não são diagnosticados, mas rotulados de pé cavum idiopático, sem que se averigue a história familial. Do ponto de vista genético, tem grande importância porque, historicamente, muitos conceitos correntes de Genética Humana foram inicialmente observados nesta doença, entre os quais heterogenia genética, relação de severidade clínica com padrão de herança e antecipação.

Neste sequência de fatos, o interesse desta comunicação se baseia na evidência de que, na casuística apresentada, parece estar envolvida, pela primeira vez, uma possivel variante do fenômeno da antecipação.

\section{OBSERVAÇOES}

CAso 1 - I.M.C., sexo feminino, 45 anos, branca, solteira. A paciente andou sem apoio desle os dois até os doze anos, quando passou a apresentar o pé esquerdo "caído" e cianótico, não podendo andar mais sozinha. Dois anos apos, lombalgia de forte intensidade, aumento com dorsoflexão e dorsoextensão, progressiva, não ficando atualmente em posição ortostática por tempo superior a cinco minutos. Cefaléia occipital bilateral, de forte intensidade, melhorando em ambiente escuro, acompanha-se de tontura e visão embaçada. Episódio de perda de consciencia há aproximadamente quinze anos, sem outros comemorativos. Alopécia progressiva há dois anos. A paciente não sabe referir

* Médico geneticista Conselho Nacional de Desenvolvimento Cientifico e Tecnológico, junto ao Laboratório de Genética Médica do Instituto de Biociéncias da Universidade de São Paulo; ** Professor Assistente do Departamento de Neuropsiquiatria da Faculdade de Ciencias Médicas e Biológicas de Botucatu. 
antecedentes obstétricos ou perinatais. Como passado mórbido, refere apenas escabiose há dois anos. De antecedentes familiares, nega consanguinidade ou ocorrência de quadro semelhante em ancestrais. Irmandade de sete elementos, cinco do sexo feminino, dos quais três com a mesma doença (a paciente, uma irmã e um irmão). Pai e mãe vivos, sem problemas de saúde. Não se detectaram alterações de exame físico (excepto pulsos pediosos não palpáveis bilateralmente) e psiquiátrico. No exame neurológico, encontraram-se, como dados positivos, dor à apalpação da coluna lombo-sacra e panturrilha esquerda; pés em varo-equino; motilidade ativa diminuida nos membros inferiores; força muscular também diminuida nos membros superiores e inferiores; hipotrofia e hipotonia muscular nos membros superiores e atrofia e hipotonia nos inferiores; arreflexia patelar, aquiliana e médio-plantar bilateral; hipotrofia masseteriana bilateral; perda de audição à direita, atrofia bilateral do externoclidomastoideo. Laboratorialmente, além dos exames habituais (sedimento urinário, protoparasitológico e hemograma) que se revelaram normais, foram realizadas as dosagens das transaminases séricas (glutâmico-oxalacética e glutamico-pirúvica) que resultaram normais. Líquido céfalorraqueano normal. Biópsia do músculo gastrocnêmico: compatível com distrofia muscular. Eletromiografia: quadríceps femural esquerdo, deltóide direito e infra-espinhoso direito com distrofia muscular progressiva; músculos tibial anterior, extensor curto dos dedos do pé esquerdo, abdutor do hálux esquerdo e primeiro interósseo da mão esquerda normais. $O$ exame mioelétrico revelou apenas hipoexcitabilidade nos músculos proximais do membro inferior esquerdo.

CAso 2 - D.C., sexo masculino, 47 anos, branco, solteiro. Comegou a andar com dificuldade aos três anos, caindo facilmente. Aos treze, notou que os pés passaram a ficar "encolhidos", aumentando progressivamente a dificuldade motora; aos 23 anos já não andava sozinho. Há cinco anos, aparecimento progressivo de lombalgia, de forte intensidade, exacerbando-se a dorsiflexão e dorso-extensão, parestesia e cianose em ambos os pés. Apresenta as mesmas alterações clínicas e neurológicas de sua irmã.

Caso 3 - M.C., sexo feminino, 33 anos, branca, solteira. A paciente começou a andar aos cinco anos, com muita dificuldade, caindo facilmente; aos 10 anos de idade observou que seus pés começaram a ficar "caídos" e "encolhidos" e cianóticos, dificultando a marcha sem apoio. AOs 13 anos, lombalgia com as mesmas características que a irmã e o irmão. Mesmas alteraçðes clínicas e neurológicas dos demais examinados.

\section{DISCUSSAO}

A atrofia muscular peronal foi inicialmente utilizada para ilustrar a "lei" de que alterações recessivas são menos severas que as dominantes e que as ligadas ao sexo tendem a ser intermediárias em severidade (McKusick, 1973) ${ }^{11}$. Allan (1939) ${ }^{1}$, a esse respeito, assevera que os indivíduos afetados pertencentes a familias onde a atrofia peronal é dominante observam o inicio do comprometimento em torno dos 30 anos, mas são capazes de continuar trabalhando até 60 , pois a atrofia é moderada. Quando a condição é recessiva ligada ao sexo, os meninos observam a atrofia no meio da segunda década e com 25 anos estão incapazes mesmo para atividades que exigem pouco esforço; quando é autossômica recessiva, inicia-se antes dos 8 anos e na segunda década o afetado já está totalmente incapacitado. Sem atingir tal relação clínico-genética, já De Lisi (1926) ${ }^{6}$ observava a existência de famílias afetadas, ora com transmissão autossômica dominante, autossômica recessiva e recessiva ligada ao sexo, numa época em que ainda se cogitava da exatidão da aplicação de conceitos básicos de genética geral ao homem, como mutação, por exemplo. Descritivamente, os homens parecem ser mais afetados que as mulheres (Beighton, 1971) ${ }^{2}$. 
No Japão, Murakami (1967) ${ }^{13}$, revendo os casos existentes até então, relata a afecção em 25 homens e 4 mulheres, com dois modelos de transmissão hereditária: originalmente teria a doença surgido com autossômica dominante, mas, ulteriormente, influenciada por penetrância reduzida, tornara-se autossômica recessiva; conclui este autor que, embora raramente documentada em várias gerações no Japão, provavelmente afete aí geralmente mais homens que mulheres.

Recentemente, estudos de condução nervosa distinguiram duas formas da doença: uma de transmissão autossômica recessiva, com comprometimento puramente neuronal (gânglios da raiz dorsal e células do corno posterior) e tempo de condução normal; outra, com condução nervosa diminuida, provavelmente com padrão de herança autossômica dominante, associada a neuropatias periféricas (Carter \& Fairbank, 1974) *.

$\mathrm{Na}$ casuística apresentada há uma irmandade acometida de atrofia peroneal em que a condição afetou três irmãos, de idades decrescentes (47, 45 e 33 anos) numa fase cada vez mais precoce, ou seja, 13, 12 e 10 anos, possivelmente revelando uma antecipação no período de manifestação da ação gênica, com a peculiaridade de tratar-se da mesma geração e não em gerações consecutivas.

Antecipação é o fenômeno pelo qual a idade de aparecimento de certas doenças (atrofia peronal, distrofia muscular, diabete melito, coréia de Huntington e distrofia miotônica) torna-se cada vez mais precoce, em gerações sucessivas. Adicionalmente, admite-se como fato independente porém concomitante, ou consequente, que se tais denças apresentam variação na severidade, esta também aumenta em gerações sucessivas.

McKusick (1971) ${ }^{10}$ associa tanto antecipação com agravamento clínico que define um pelo outro: "Antecipação é a expressão mais grave de um distúrbio em determinada geração do que na geração ou gerações anteriores. Assim, se fizermos um gráfico da distribuição da gravidade da doença, obteremos uma curva em forma de sino: os afetados da primeira geração que tiveram filhos ocupam o extremo mais benigno da curva, enquanto seus descendentes afetados ocupam mais uniformemente a curva toda; a segunda geração é, em média, mais severamente afetada que a primeira."

Penrose (1947) ${ }^{14}$ estudando o fenômeno da antecipação especificamente em afetados de distrofia miotônica, conclui que a correlação observada entre idade de aparecimento da doença em páis e filhos é coerente com a hipótese de que o grau de manifestação do gene principal da doença depende do gene alélico. A este respeito, Fisher (1935) ${ }^{8}$ propõe que ao longo da evolução, genes modificadores alterariam a relação de dominância do gene: possivelmente no homem primitivo a doença fosse característica da velhice; com sua antecipação em gerações sucessivas, futuramente se manifestará já na primeira infância. No entanto, mais recentemente Childs e Kaloustian (1968) 5 revendo os conceitos de gene principal e gene modificador, afirmam que, a nível molecular, todos os genes são tanto principais como modificadores e que a manifestação metabólica de qualquer um é, em menor ou maior grau, dependente da ação de, pelo menos, muitos genes.

Stern (1960) ${ }^{16}$ revendo o assunto, propõe algumas possíveis fontes de distorções, que comprometem a existência real do fenômeno da antecipação: 1) Con- 
dições ambientais desconhecidas relacionadas indiretamente com a doença podem ter modificado ao longo do tempo, antecedendo o início da manifestação da doença em gerações mais recentes. 2) Pode ocorrer que as famílias estudadas não sejam representativas da população afetada e, assim, o fenômeno não caracteriza a doença. Este tipo de desvio poderia ocorrer por seleção de pais afetados em que o início da doença é precoce ou por seleção de casos com início simultâneo em pais e filhos. 3) Outros tipos de desvios também podem ocorrer. Por exemplo, apenas indivíduos de geração mais antiga com aparecimento mais tardio da doença têm descendência e, assim, se tornam viáveis para registro. Se a idade média do aparecimento em seus filhos fosse a mesma que na geração não selecionada anterior, seria mais precoce que no grupo selecionado que se tornou conhecido apenas porque a doença começou tarde. De fato, é provável, por exemplo, que individuos da presente geração não saibam, ou tenham esquecido, da existência em seus ancestrais de um início precoce da doença.

Poderiamos, adicionalmente, recordar o fato habitual de que pessoas que já tiveram um afetado familiar por doença grave, tendem a procurar uma detecção precoce do mesmo evento em seus descendentes.

Quanto à antecipação na mesma irmandade, não há referências de estudos profundos a respeito, seja para condições humanas patológicas em geral, seja para a atrofia peroneal em particular, sabendo-se que não existe, por exemplo, na coréia de Huntington (Brackenridge, 1972) ${ }^{3}$. No entanto, no caso vertente, em que esta hipótese pode ser aventada, não há abundância de dados, pela própria condição biológica da família que permita um tratamento genético-matemático mais elaborado: ainda que os afetados apresentem realmente uma idade decrescente de instalação do processo, existem apenas três afetados.

Deste modo, permanece registrado o fato observado, à espera de evidências adicionais ulteriores ou fruto de uma circunstância fortuita. No dizer de Mulvihill e Smith (1969) 12 "os fenômenos biológicos raramente apresentan precisão matemática e os similares podem ser coincidências".

\section{RESUMO}

Considerando-se a peculiaridade genética da atrofia peroneal de CharcotMarie-Tooth, é feita a descrição clínica de familia com três irmãos afetados, com idade de aparecimento progressivamente antecipada, refletindo possivel variante do fenômeno da antecipação, condição inusitada na literatura, não só para esta doença, mas também, de modo geral, em Genética Humana.

\section{SUMMARY}

Sibship affected by Charcot-Marie-Toot's peroneal muscular atrophy with possible variant of antecipation.

Considering the genetical peculiarity of Charcot-Marie-Tooth's muscular atrophy, a family with three affected brothers was investigated, in which beginning 
date was discovered to be progressively antedated. Afterwards, this possible variant of antecipation is discussed, because such condition is quite ununsual, not only in this disease, but in Human Genetics, in a general sense.

\section{REFERENCIAS}

1. ALLAN, W. - Relation of hereditary pattern to clinical severity as illustrated by peroneal atrophy. Arch. Int. Med. 63:1123, 1939.

2. BEIGHTON, P. H. - Charcot-Marie-Tooth syndrome, dominantly inherited. In The Sec. Conf. Clin. Del. - Birth Defec.: Original art. ser. 7:108, 1971.

3. BRACKERINDGE, C.G. - The relation of birth order to age of onset of Huntington's disease. Human Her. 22:584, 1972.

4. CARTER, C. D. \& FAIRBANK, T. A. - Peroneal muscular atrophy (CharcotMarie-Tooth). In The Genetics of Locomotor Diseases. Oxford Monographs on Medical Genetics, 138, 1974.

5. CHILDS, C. D. \& DER KALOUSTIAN, V. - The genetic heterogeneity. New Engl. J. Med. $279: 1205,1968$.

6. DE LISI, L. - Osservazioni e studi sulla transmissione ereditaria dell'atrofia muscolare tipo Charcot-Marie. Riv. Pat. Ner. Ment. 31:390, 1926.

7. DYCK, P. J. - Charcot-Marie-Tooth disease: nerve conduction and clinical stu lies of a large kinship. Neurology 13:1, 1963.

8. FISHER, A. - apud HALDANE, J. B. S.

9. HALDANE, J. B. S. - The relative importance of principal and modifying genes in determining some human disease. J. Genet. 41:149, 1941.

10. MaKUSICK, V. A. - Genética Humana. Versăo brasileira. Editora da Universidade de São Paulo, 1971.

11. McKUSICK, V. A. - Charcot-Marie-Tooth Peroneal Muscular Atrophy. Mendelian Inheritance in Man. Johns Hopkins University Press, Baltimore, pag. 340, 1973.

12. MULVIHILL, J. J. \& SMITH, D. W. - The genesis of dermatoglyphics. J. Pediat. $75: 579,1969$.

13. MURAKAMI, U. - Hereditary disorders of the nervous system in isolates of Japan. J. Gen. Humaine 13:265, 1964.

14. PENROSE, L. S. - The problem of antecipation in pedigrees of dystrophia myotonica. Ann. Eugn. (London) 14:125, 1947.

15. PRATT, R. T. C. - Peroneal muscular atrophy. In The Genetics of Neurological Disorders. Oxford Univ. London, pag. 82, 1967.

16. STERN, C. - Antecipation. Princ. Hum. Gen.: 322. Freeman, San Francisco, 1960.

Laboratorio de Genética Medica - Fraculdade de Medicina, Universidade de são Paulo - Caixa Postal 8921 - 01000 sao Paulo, SP - Brasil. 